\title{
Práticas pedagógicas com recursos digitais: instrucionistas ou construtivistas?
}

\section{Pedagogical practices with digital resources: instructionalists or construtivists?}

\section{CACILDA ENCARNAÇÃO AUGUSTO ALVARENGA}

Centro Universitário da Fundação Hermínio Ometto

\begin{abstract}
Resumo: O conhecimento de como Recursos digitais (RD) estão sendo usados didaticamente pode auxiliar na visualização de novas práticas e a repensar programas de formação para o uso de Tecnologias Digitais de Informação e Comunicação (TDIC) no ensino. O estudo teve como objetivos identificar quais são os RD utilizados por 81 professores de Ensino Fundamental e Médio das disciplinas Ciências, Biologia, Física, Química e Matemática; como eles os encontram; qual a principal finalidade com que os utilizam e quais as práticas pedagógicas adotadas. Os dados foram coletados por meio de um questionário e analisados quantitativa e qualitativamente. Os professores têm se apropriado de RD desenvolvidos por instituições governamentais, localizando-os principalmente via buscadores, sendo vídeo o RD mais utilizado. Os RD são utilizados sobretudo para motivar os alunos. As abordagens instrucionista e construtivista vem sendo adotadas, com predominância da construtivista. O estudo revela mudanças nas práticas pedagógicas com o uso de TDIC. Os professores têm reconhecido a importância de abordagens que envolvam a exploração de TDIC não apenas por eles, mas também pelos alunos.
\end{abstract}

Palavras-chave: Recursos digitais. Práticas pedagógicas. Tecnologias Digitais de Informação e Comunicação no ensino.

\begin{abstract}
The knowledge of how digital resources (DR) are being used can help in the visualization of new practices and rethinking training programs for the use of digital information and communication technologies (DICT) in teaching. The study had as objectives to identify which are the DR used by 81 teachers of Elementary and Secondary School of Sciences, Biology, Physics, Chemistry and Mathematics; how they find them; the main purpose for which they are used and the pedagogical practices adopted. The data were collected through a survey and were analyzed quantitatively and qualitatively. Teachers have appropriated resources developed by government institutions, which are mainly located by search engines and video is the RD most used. RDs are mainly used to motivate students. The instructionalist and constructivist approaches have been adopted, with predominance of constructivist. The study reveals changes in pedagogical practices with the use of DICT. Teachers have recognized the importance of approaches that involve the exploration of DICT not only by them, but also by students.
\end{abstract}

Keywords: Digital Resources. Pedagogical practices. Digital Information and Communication Technologies in teaching. 


\section{Introdução}

O entendimento de que recursos digitais ${ }^{1}(\mathrm{RD})$ podem contribuir para o processo de ensino e aprendizagem tem levado professores a utilizá-los em suas aulas. Estudos mostram que eles podem auxiliar a motivar os alunos para os estudos, a reverem conceitos previamente estudados e também participarem mais ativamente das aulas (CARNEIRO; PASSOS, 2014; RATOMPOMALALA; BRUILLARD; RAZAFIMBELO, 2012; KAY; KNAACK, 2008).

RD que incorporam diversas mídias (escrita, visual e sonora) possibilitam a apresentação de conteúdos de forma lúdica e dinâmica, facilitam o entendimento de conceitos considerados abstratos, difíceis de serem entendidos apenas a partir da leitura de um texto ou da explicação oral do professor. Bates (2015) lembra que um vídeo, por exemplo, pode favorecer o processo de ensino e aprendizagem ao possibilitar a visualização de fenômenos considerados grandes, microscópicos, caros, inacessíveis ou difíceis de serem observados sem equipamentos especiais.

Projetos e iniciativas governamentais foram implementados em diversos países com o propósito de desenvolver recursos ou conteúdos multimídia para uso gratuito de professores e alunos e assim também incentivar o uso de Tecnologias Digitais de Informação e Comunicação no ensino.

Em 2007, o Ministério de Ciência e Tecnologia e o Ministério da Educação publicaram um edital para apoiar financeiramente projetos que envolvessem a produção de conteúdos educacionais digitais. A proposta era que os conteúdos apoiassem o trabalho dos professores no Ensino Médio e contribuíssem para a melhoria e a modernização dos processos de ensino e aprendizagem na rede pública (BRASIL, 2007). Em 2008, foi lançado o Portal do Professor2, um espaço na internet que disponibiliza aos professores recursos multimídia (ex. imagens, animações e vídeos), informações ou links para acesso a outros conteúdos de interesse didático ou voltados para a formação docente, como cursos ou materiais de estudo. É um espaço que tem como objetivo também possibilitar a interação e a colaboração entre professores. Eles podem compartilhar materiais como sugestões de atividades ou aulas.

O Projeto RIVED33 (Rede Interativa Virtual de Educação) é uma outra iniciativa, existente no Brasil desde 1999, que tem como objetivo produzir e compartilhar conteúdos digitais, no formato de objetos de aprendizagem ou recursos que possam favorecer o processo de ensino e aprendizagem (ex. atividades multimídias no formato de animações, simulações). Ele está sob a responsabilidade da Secretaria da Educação a Distância - SEED e desde 2004 os conteúdos são desenvolvidos em parceria com universidades.

\footnotetext{
1 Recursos digitais são objetos digitais como imagens, animações, simulações e softwares que podem ser acessados utilizando-se de um computador ou de um dispositivo eletrônico digital. Considerando Smith (2004), pode-se compreender que recursos digitais, quando utilizados e/ou reutilizados no ensino, em situações didáticas com diferentes objetivos pedagógicos, podem ser denominados também objetos de aprendizagem. No presente artigo, optou-se por usar o termo recursos digitais (RD).

2 http://portaldoprofessor.mec.gov.br/index.html

3 http://rived.mec.gov.br
} 
Diversas Secretarias da Educação também criaram seus portais de conteúdo multimídia sinalizando aos professores novas possibilidades de trabalho pedagógico, incentivando o uso de tecnologias no ensino.

Além dos portais educacionais de conteúdo vinculados a órgãos públicos e privados, desenvolvidos especialmente para fins pedagógicos, há diversos recursos digitais disponíveis na rede, localizados com o auxílio dos buscadores como o Google, que podem ser utilizados em situações de ensino dependendo da visualização de seu uso didático pelo professor.

Diante da diversidade de conteúdos educacionais existentes, da ampliação do acesso à internet e da crença de que as tecnologias podem favorecer o processo de ensinar e aprender, questiona-se: quais são os recursos ou conteúdos digitais que vem sendo utilizados por professores? Como eles estão os utilizando didaticamente? Entende-se que identificar RD e práticas pedagógicas permite conhecer como eles estão sendo integrados ao ensino e também compartilhar saberes com professores que ainda não os utilizam.

\subsection{Uso didático das Tecnologias Digitais de Informação e Comunicação (TDIC)}

De acordo com a literatura nacional e internacional, a forma que os professores utilizam as tecnologias nem sempre considera o seu potencial e o que os alunos podem realizar com a mediação pelo professor. Estudos, como os de Ribeiro (2010), Ministère de l' Éducation Nationale (2012), Ghavam (2013) e Henrique (2016), mostram que as práticas pedagógicas muitas vezes se aproximam demais daquelas que acontecem sem o uso dos recursos, não consideram, por exemplo, as possibilidades de interação por eles oferecidas ou não costumam envolver o uso das tecnologias pelos alunos.

Segundo Coll, Mauri e Onrubia (2010), a compreensão e avaliação do impacto das Tecnologias Digitais de Informação e Comunicação (TDIC) na educação escolar devem considerar não apenas as características das tecnologias e os seus efeitos sobre os resultados de aprendizagem, mas também as atividades que professores e alunos podem desenvolver a partir das possibilidades de acesso, processamento de informação e de comunicação que elas oferecem. A simples incorporação das TDIC à educação ou o uso não é suficiente para transformar, inovar as práticas educacionais e melhorar processos de ensino e aprendizagem.

Uma pesquisa realizada por Ribeiro (2010) com professores brasileiros de 24 escolas de Educação Básica da rede pública e privada constatou que eles tinham pouca familiaridade com as tecnologias digitais e não visualizavam como utilizá-las didaticamente. A maior parte das atividades realizadas pelos professores no laboratório de informática assemelhava-se as aulas tradicionais, voltando-se para a memorização e reprodução de conteúdos e não para o favorecimento da descoberta, produção individual e/ou coletiva e avaliação crítica de informações disponíveis na internet. Segundo a autora, embora nas escolas que pesquisou, ocorram práticas pedagógicas que promovem a leitura, a produção escrita e a pesquisa em ambientes virtuais, pouco tem sido feito para que os alunos adquiram habilidades relacionadas "ao manuseio crítico e constante de informações e uso dessas últimas para a construção 
individual e coletiva do conhecimento, a interagir com outros usuários da rede para os mais diversos fins" (p. 13).

Dados semelhantes ao de Ribeiro (2010) foram encontrados também em uma pesquisa mais recente realizada por Henrique (2016), cujos dados foram coletados em uma escola da rede privada, também no Brasil. A maioria dos professores de Ensino Fundamental participantes do estudo mostrou dificuldade em usar as TDIC de forma a considerar o seu potencial, propondo atividades que levassem os alunos a refletirem sobre informações divulgadas na internet. Notou-se que os professores reproduziam sempre as mesmas práticas, como usar o computador para mostrar vídeos, imagens, acessar textos e realizar pesquisas, mas não para o desenvolvimento de tarefas consideradas mais interativas como as voltadas à discussão, por exemplo, da veracidade dos conteúdos publicados na internet ou à produção de conteúdos.

Krawczyck (2009) a partir de estudos anteriores a essa sua publicação, cujos dados foram coletados em escolas brasileiras, já alertava sobre uso pedagógico meramente técnico da informática na escola, pouco capaz de trazer contribuições ao processo de ensino e aprendizagem. Segundo a autora, o interesse dos alunos pelas mídias precisa ser considerado pela escola, que deve ensiná-los a utilizarem as mídias criticamente. Carneiro e Passos (2014, p.112) lembram que "a introdução das TIC e de tarefas de caráter exploratório-investigativas será mais um desafio para o professor: ele terá que aprender a realizar tarefas abertas, nãodiretivas, a levantar hipóteses e a discutir e argumentar com seus alunos".

Um olhar para estudos internacionais revela que as práticas pedagógicas com TDIC não diferem muito de um país para outro.

Uma pesquisa4 realizada em 2012 com 3270 professores franceses, das séries finais do Ensino Fundamental e de Ensino Médio, que buscou investigar o uso didático de TDIC, constatou que apesar da maioria dos professores afirmar que elas podem motivar os alunos para os estudos, tornando as aulas mais interessantes, elas são ainda usadas principalmente para preparar aulas, registrar ausências e notas de avaliações. Atividades que envolvem o uso direto das tecnologias pelos alunos foram pouco mencionadas. Dados desse mesmo estudo revelam que os professores reconhecem que a tecnologia não é ainda usada como poderia (MINISTĖRE DE L' ÉDUCATION NATIONALE,2012). Em escolas francesas, em que professores e alunos têm acesso a computadores portáteis, percebe-se que muitos professores não solicitam que os alunos realizem atividades com seus computadores. Esse fato faz com que os alunos questionem a razão de terem que levar o computador para a escola diariamente (GHAVAN, 2013).

Contata-se que embora as tecnologias tenham evoluído, novos recursos e aplicativos tenham surgido, os resultados de estudos realizados a partir de 2010, referentes à prática pedagógica dos professores utilizando-se dos recursos, como os da pesquisa PROFETIC (Ministère de l' Éducation Nationale, 2012), não diferem dos realizados em anos anteriores e em outros países. Um estudo realizado em escolas de Ensino Médio e Fundamental da Espanha

4 Chamada PROFETIC, desenvolvida pelo Ministério da Educação da França. 
durante os anos letivos de 2005 e 2006, constatou que o uso mais frequente 5 das TDIC no ensino estava relacionado principalmente ao trabalho pessoal do professor (utilização do editor de textos, busca de informação na internet, gerenciamento do trabalho pessoal e preparação de aulas), sendo menos frequentes os usos de apoio ao trabalho docente na aula (por exemplo, para fazer apresentação, simulações, utilização de software educacional etc) e praticamente inexistentes os relacionados ao uso direto das TIC pelos alunos (por exemplo, para realizar trabalhos que envolvem a comunicação e colaboração) (INSTITUTO DE EVALUACIÓN Y ASESORAMIENTO EDUCATIVO, NETURITY Y FUNDACIÓN GERMÁN SÁNCHEZ RUIPÉREZ, 2007). "Há uma defasagem considerável entre a atitude positiva e a elevada valorização que o professorado expressa e tem das TIC e o uso limitado que é dado a elas na prática docente" (COLL; MAURI; ONRUBIA, 2010, p.73).

\subsection{Concepções de aprendizagem e abordagens pedagógicas}

Entende-se como importante considerar que o papel que os professores atribuem aos recursos tecnológicos e a estratégia de ensino que adotam estão relacionadas às suas concepções de ensino e aprendizagem, ao seu conhecimento do conteúdo, de métodos de ensino e aprendizagem e também das tecnologias (SIGALÉS, 2008 apud COLL; MAURI; ONRUBIA, 2010; SHULMAN, 1986, MISHRA; KOEHLER, 2006).

As concepções de ensino e aprendizagem são fundamentadas em teorias da aprendizagem. Entre as principais teorias da aprendizagem estão as apresentadas pela Psicologia Educacional, como a Behaviorista, Psicogenética e Sócio-Histórica. Para a teoria Behaviorista ou Comportamentalista, que tem Burrhus Frederic Skinner (1904-1990) como o seu principal representante, a aprendizagem é toda a relação do indivíduo com eventos antecedentes (estímulos) e consequentes (respostas) que produzam mudança no seu comportamento. A teoria Psicogética formulada por Jean Piaget (1918-1980) entende a aprendizagem como um processo ativo de construção de conhecimentos, e não uma recepção passiva de informações (COLL, 1992). A Sócio-Histórica representada por Lev Semenovich Vygotsky (1896-1934) considera a aprendizagem como sendo o processo pelo qual o indivíduo adquire informações, habilidades, atitudes, valores etc a partir do seu contato e interação com a realidade, com o meio ambiente e com as outras pessoas (OLIVEIRA, 2002). É importante considerar que embora cada uma das teorias tenham os seus próprios princípios, todas elas trazem importantes contribuições ao processo de aprendizagem. O fato também de uma determinada teoria, ou autor, não ter enfatizado um determinado princípio ou concepção, não significa que para ele, esse princípio não exista.

Abordagens pedagógicas ou estratégias de ensino consideram pressupostos de teorias da aprendizagem, como por exemplo, as abordagens instrucionista e interacionista ou construtivista. Behar (2009) e Mesquita, Piva e Gara (2014) as definem considerando a sua aplicação em um ensino presencial ou à distância que seja mediado por tecnologias. A abordagem instrucionista é aquela que defende que o conhecimento é transmitido ou

5 Várias vezes na semana ou todos os dias. 
transferido para o sujeito (BEHAR, 2009). O conteúdo geralmente é apresentado de forma expositiva. O aluno verifica se compreendeu as informações, individualmente, por meio de exercícios, por exemplo de múltipla escolha, autocorrigíveis pelo sistema, que apontam os resultados instantaneamente. Após cada objetivo de aprendizagem atingido ele recebe um comentário (MESQUITA; PIVA; GARA, 2014). A abordagem interacionista defende que o aluno constrói o seu próprio conhecimento, que a aprendizagem ocorre a partir da ação, da (inter)ação entre o sujeito e o meio exterior (o objeto) (BEHAR, 2009). A escolha das atividades pedagógica e dos recursos didáticos está centrada na interação entre o aluno, 0 conteúdo e os sujeitos envolvidos no processo de ensino e aprendizagem (alunos e professores). Valoriza-se a aprendizagem colaborativa. Trabalhos em grupo são propostos, utilizando-se de ferramentas que facilitam a interação como fórum, chat e aplicativos de mensagens instantâneas (MESQUITA; PIVA; GARA, 2014). Compreende-se que a abordagem construtivista, ao valorizar a interação do aluno, vai ao encontro também das metodologias ativas. De acordo com Moran (2018), metodologias ativas correspondem a estratégias de ensino que enfatizam o protagonismo do aluno, o seu envolvimento, participação no processo de ensino e aprendizagem, realizando diversas atividades sob a orientação do professor. Segundo Valente, Almeida e Geraldini (2017), as metodologias ativas envolvem os alunos em atividades que demandam um comportamento mais ativo, que lhe permitem aprender ou construir conhecimentos a partir de relações que estabelece com o contexto em que está inserido, o que envolve, por exemplo, considerar a cultura digital e fatos do seu cotidiano. Para os autores "repensar novas propostas educativas que superem a instrução ditada pelo livro didático, centrada no dizer do professor e na passividade do aluno" é um dos desafios colocados à educação (VALENTE; ALMEIDA; GERALDINI, 2017, p.458).

Professores que têm uma concepção de ensino e aprendizagem mais transmissiva ou tradicional tendem a utilizar as TDIC em estratégias que voltam-se para a apresentação e transmissão de conteúdo, enquanto os que têm uma concepção mais "construtivista" ou ativa tendem a utilizá-las para promover atividades de exploração ou indagação dos alunos, que eles possam realizar individual ou coletivamente (SIGALÉS, 2008 apud COLL; MAURI; ONRUBIA, 2010).

Mishra e Koehler (2006), a partir da teoria Pedagogical Content Knowledge (PCK) ${ }^{6}$ de Schulman (1986), formularam a abordagem teórica Technological Pedagogical Content Knowledge $(\text { TPCK })^{7}$. A teoria PCK de Schulman (1986) refere-se a necessidade de que o professor tenha conhecimento do conteúdo a ser ensinado e de estratégias (analogias, ilustrações, exemplos, demonstrações entre outros) que podem ser utilizadas. O professor deve ser capaz de identificar quais delas podem facilitar ou dificultar a aprendizagem de um determinado conteúdo, considerando também as características dos diferentes tipos de estudantes, como idade e conhecimentos prévios. Segundo Wilson, Shulman e Richert (1987) é muito importante que os professores conheçam não apenas conceitos, princípios e teorias, ou o

\footnotetext{
6 Conhecimento Pedagógico do Conteúdo

7 Conhecimento Tecnológico Pedagógico do Conteúdo
} 
conteúdo, mas também diferentes caminhos ou maneiras de apresentá-los ou comunicá-los aos alunos considerando os objetivos de ensino que se pretende atingir. De acordo com Martín e Solé (2004, p.75), há conteúdos e objetivos que são melhores ensinados por meio de estratégias de ensino diferentes da exposição, pois "sua aprendizagem requer algo mais e diferente da recepção, como a prática reflexiva, a exercitação, os processos de tomada de decisões em grupo etc".

A abordagem TPCK de Mishra e Koehler (2006) entende que saber usar TDIC no ensino de forma que favoreçam a aprendizagem é um dos papéis do professor. Ensinar exige dominar e relacionar diversos tipos de conhecimentos: do assunto ser ensinado (conteúdo), de estratégias de ensino e aprendizagem (pedagógico) e também das tecnologias disponíveis (tecnológico). Para os autores, TPCK é essencial para um bom ensino usando tecnologias. Ela exige o entendimento da representação de conceitos usando tecnologias, o conhecimento de técnicas pedagógicas que usam tecnologias em caminhos construtivos para ensinar o conteúdo, de como os conceitos podem ser aprendidos e como a tecnologia pode ajudar a resolver dificuldades dos estudantes.

\section{Objetivos}

A compreensão de que recursos digitais (RD) podem contribuir no processo de ensino e aprendizagem e que identificar como estão sendo usados didaticamente pode auxiliar no processo de integração das TDIC no ensino, na visualização de novas práticas pedagógicas, bem como a repensar programas de formação continuada para o uso de TDIC no ensino, motivou a realização do presente estudo que teve os seguintes objetivos: a) identificar quais são os recursos digitais que vem sendo utilizados por professores brasileiros de Ensino Fundamental e Médio no ensino das disciplinas Ciências, Biologia, Física, Química e Matemática; b) como eles encontraram ou conheceram o recurso; c) qual a principal finalidade com que os utilizam e d) quais as práticas pedagógicas (atividades e abordagens de ensino) que vem sendo adotadas com esses recursos.

\section{Método}

O estudo8 envolveu uma coleta de dados de natureza quantitativa e qualitativa. Os procedimentos para desenvolvê-lo foram aprovados por um Comité de Ética em Pesquisa (Parecer número: 762.217).

\subsection{Participantes}

Participaram da pesquisa 81 professores brasileiros dos anos finais do Ensino Fundamental ( $5^{\circ}$ ao 90 ano) e Ensino Médio, de escolas públicas e privadas, sendo 31 de Ciências e Biologia, 15 de Física e Química e 35 de Matemática. Os professores eram em sua maioria do sexo feminino (70\%), tinham uma média de idade de 42 anos (desvio padrão de 10 anos) e estavam distribuídos entre 7 estados ( $A M, D F, M G, P R, R N, S C$ e SP). A maioria residia nos estados do

8 O estudo teve o apoio financeiro da Coordenação de Aperfeiçoamento de Pessoal de Nível Superior (CAPES), Processo BEX 17.818/12-5. 
Paraná (40\%) e São Paulo (35\%). Quando participaram do estudo, eles tinham concluído a formação inicial para lecionarem há uma média de 14 anos (desvio padrão de 10 anos) e tinham em média 16 anos de experiência docente (desvio padrão de 11 anos).

\subsection{Instrumento}

Os dados foram coletados por meio de um Questionário elaborado a partir de pesquisas anteriores sobre o uso de RD ou objetos de aprendizagem, em especial as de Kay e Knaack (2007, 2008 e 2009), uma pesquisa sobre o uso de tecnologias no ensino conduzida pelo Ministério da Educação da França (Pesquisa PROFETIC conduzida em junho de 2012) e experiências profissionais e acadêmicas do pesquisador responsável pelo estudo. O questionário tinha 35 questões fechadas e abertas, as quais voltavam-se para caracterizar o participante em relação a variáveis pessoais (idade, sexo, estado em que o professor leciona, disciplina que leciona, tempo que finalizou a sua formação inicial para se tornar professor e tempo de experiência docente) e variáveis relacionadas ao uso de RD disponíveis gratuitamente na internet (ex. tipo de RD mais usado, estratégia de ensino adotada quando usa RD, principal finalidade de uso e como pesquisam e localizam RD). Para verificar se as questões estavam claras aos participantes e se o questionário atendia aos objetivos de pesquisa, ele foi testado com um grupo de 16 professores que tinham o perfil da amostra. Para o presente estudo foram considerados dados em especial das questões abertas, que solicitavam ao professor para informar um RD disponível gratuitamente na internet que tinha o hábito de utilizar, mencionando o seu endereço eletrônico, objetivo pedagógico com que o utilizava e descrição de como o usava.

Os professores participantes concordaram com um Termo de Consentimento Livre e Esclarecido (TCLE) antes de responderem ao instrumento. Esse termo explicava os objetivos do estudo, que a participação era voluntária e confidencial, que os dados seriam usados apenas para fins acadêmicos e que não haveria benefícios diretos aos participantes.

\subsection{Procedimento para coleta e análise dos dados}

O questionário foi disponibilizado em um software online para a coleta e análise de dados, chamado Sphinx, o qual gerou um link a ser divulgado aos professores. A divulgação foi feita, via e-mail, a professores e coordenadores pedagógicos de escolas da rede de contatos do pesquisador responsável e também a coordenadores de cursos de formação de professores para o uso de tecnologias no ensino. O convite à participação no estudo também foi publicado em uma rede social.

As respostas para as questões fechadas foram analisadas quantitativamente por meio da estatística descritiva utilizando o software SAS (Statistical Analysis System). As respostas para as questões abertas foram analisadas considerando a análise de conteúdo de Bardin (1995). Segundo a autora, a análise de conteúdo envolve a organização do material ou dados coletados, a definição de temas ou categorias de análise e o tratamento dos dados que envolve os processos de inferência e interpretação, considerando os objetivos do estudo e a fundamentação teórica. 
No caso do presente estudo, por exemplo, inicialmente as respostas abertas referentes à prática pedagógica com o recurso digital foram organizadas em um único documento. Elaborou-se, três documentos ${ }^{9}$ : um que centralizou os dados dos professores de Ciências e Biologia, outro dos professores de Física e Química e outro dos professores de Matemática. Na sequência, a descrição das práticas dos professores de todas as disciplinas foram organizadas em uma planilha. As respostas foram interpretadas, identificou-se e quantificou-se as respostas que referiam-se a duas categorias: práticas instrucionistas e práticas construtivistas. As categorias foram definidas considerando a literatura: Behar (2009); Mesquita, Piva e Gara (2014); Sigalés (2008 apud Coll; Mauri; Onrubia, 2010). As práticas pedagógicas classificadas como instrucionistas são aquelas que fazem uso dos RD (ex. vídeos ou imagens) na explicação de conteúdos ou conceitos, de forma expositiva. Ao final da exposição, solicita-se aos alunos a realização de uma atividade como a resolução de um exercício. As práticas classificadas como construtivistas caracterizam-se principalmente por demandar que o aluno acesse ou explore o RD, como um software ou simulação, seja no momento da aula ou em outro momento posterior. Solicita-se aos alunos atividades que estejam relacionadas a exploração do RD.

\section{Resultados}

Embora o instrumento utilizado no estudo solicitasse aos professores para fornecerem informações sobre sobre 1 (um) RD (ex. imagem, simulação, vídeo10) que tinham o hábito de usar nas suas aulas e que está disponível na internet gratuitamente, a maioria preferiu mencionar o site ou portal que localizam RD, não mencionando, portanto, um RD em especial. Os portais mais citados foram: Dia a Dia Educação-Secretaria da Educação do Paraná, Rived, o buscador de vídeos Youtube e o buscador Google.

As Tabelas de 1 a 3 e o Anexo 1 apresentam a relação de portais ou RD que vem sendo usados pelos professores. O Anexo 1 informa a disciplina, ano, assuntos trabalhados e os endereços específicos de cada um dos RD ou portais mencionados. Apesar de existir uma indicação do ano e nível de ensino que o recurso vem sendo utilizado, entende-se que vários deles podem ser usados com alunos de outros anos e níveis. A não correspondência entre o número de professores participantes do estudo e o número de RD ou portais apresentados, bem como de práticas relatadas, justifica-se devido a repetição dos mesmos/as (determinados recursos foram mencionados por diversos professores) ou então a não terem sido relatados.

A Tabela 1 apresenta a relação de portais mencionados por professores de Ciências e Biologia. O portal mais citado foi o Dia a Dia Educação.

\footnotetext{
9 Esses documentos foram criados com o objetivo principal de compartilhar práticas pedagógicas com o uso de RD ou
} objetos de aprendizagem e estão disponíveis nos endereços indicados no Anexo 2. 
Tabela 1 - Portais citados por professores de Ciências e Biologia

\begin{tabular}{|l|c|c|}
\hline \multicolumn{1}{|c|}{ Portais citados de Ciências e Biologia } & Frequência & $\%$ \\
\hline Atica Educacional & 3 & 10 \\
\hline Dia a Dia Educação-Secretaria da Educação do Paraná & 14 & 46,1 \\
\hline Google & 4 & 12 \\
\hline Portal do Professor & 1 & 3,3 \\
\hline Racha Cuca & 1 & 3,3 \\
\hline Rived MEC & 1 & 3,3 \\
\hline Youtube & 4 & 12 \\
\hline Nao especificaram & 3 & 10 \\
\hline Total & $\mathbf{3 1}$ & $\mathbf{1 0 0}$ \\
\hline
\end{tabular}

Fonte: $\mathrm{O}$ autor.

Conforme podemos observar na Tabela 2, novamente o Portal Dia a Dia Educação é o mais citado também por professores e Física e Química. Nota-se que aparece nessa relação dois portais internacionais: o PHT Interactive Simulations University of Colorado (EUA) e o SoftCiências Faculdade de Ciências da Universidade do Porto (Portugal).

Tabela 2- Portais citados por professores de Física e Química

\begin{tabular}{|l|c|c|}
\hline \multicolumn{1}{|c|}{ Portais citados de Física e Química } & Frequência & $\%$ \\
\hline A Graça da Quimica & 1 & 6,66 \\
\hline Dia a Dia Educação - Secretaria da Educação do Paraná & 5 & 33,36 \\
\hline Google & 1 & 6,66 \\
\hline PHT Interactive Simulations University of Colorado & 1 & 6,66 \\
\hline Portal do Professor & 1 & 6,66 \\
\hline Rived MEC & 1 & 6,66 \\
\hline Só Física & 1 & 6,66 \\
\hline SoftCiências Faculdade de Ciências da Universidade do Porto & 1 & 6,66 \\
\hline Youtube & 2 & 13,36 \\
\hline Não especificaram & 1 & 6,66 \\
\hline Total & $\mathbf{1 5}$ & $\mathbf{1 0 0}$ \\
\hline
\end{tabular}

Fonte: $\mathrm{O}$ autor.

O buscador Google foi citado por $20 \%$ dos professores de Matemática, seguido do Youtube, Portal Dia a dia Educação e do software de geometria dinâmica Geogebra. 22,5\% dos professores não especificaram o recurso ou portal que utilizam. Eles mencionaram que não se lembravam do endereço, que não tinham como informar no momento que estavam participando do estudo, ou informaram nomes que não foram localizados em uma pesquisa em 
buscadores. Podemos observar que na relação há dois softwares: o Geogebra e o Microsoft Mathematiques.

Tabela 3 - Portais citados por professores de Matemática

\begin{tabular}{|l|c|c|}
\hline \multicolumn{1}{|c|}{ Portais citados de Matemática } & Frequência & $\%$ \\
\hline Brasil Escola & 1 & 2,85 \\
\hline Dia a Dia Educação - Secretaria da Educação do Pa & 5 & 14,5 \\
\hline Geogebra & 4 & 11,4 \\
\hline Google & 7 & 20 \\
\hline Microsoft Mathematiques & 1 & 2,85 \\
\hline Oswego. Org & 1 & 2,85 \\
\hline Rived MEC & 1 & 2,85 \\
\hline So Matematica & 1 & 2,85 \\
\hline Youtube & 6 & 17 \\
\hline Nao especificaram & 8 & 22,85 \\
\hline Total & $\mathbf{3 5}$ & $\mathbf{1 0 0}$ \\
\hline
\end{tabular}

Fonte: O autor.

Vídeos e imagens estão entre os RD mais usados pelos professores. Softwares é o tipo de recurso usado principalmente pelos professores de Matemática (Figura 1).

Figura 1- Tipo de RD que os professores mais utilizam

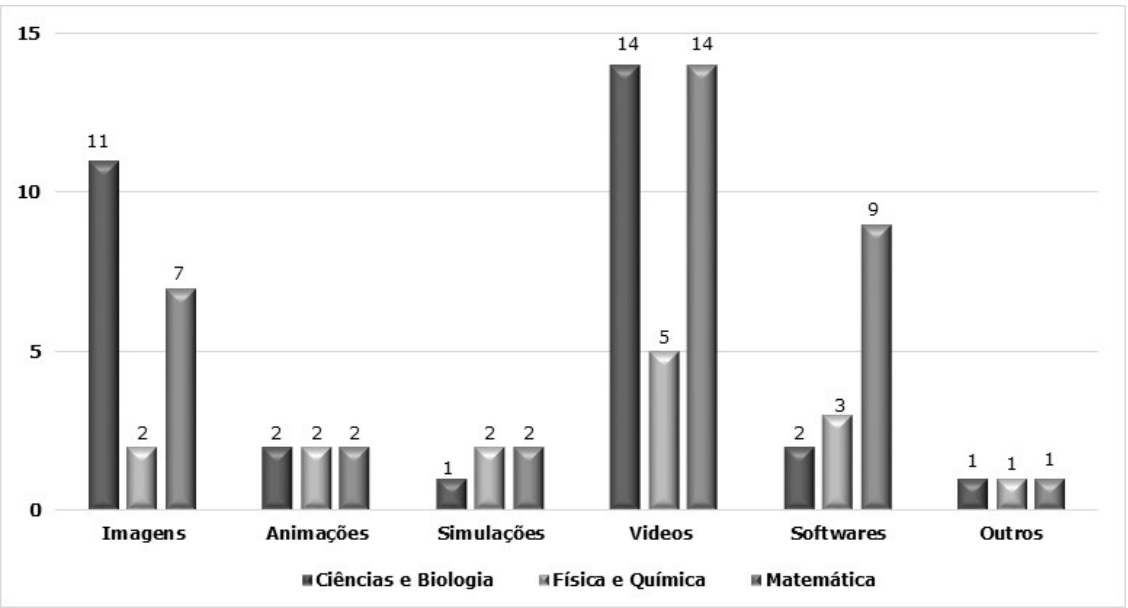

Fonte: O autor

Os professores que mencionaram "Outros" disseram utilizar principalmente textos.

Um número considerado significativo de professores $(\mathrm{N}=39)$ mencionou ter descoberto o RD mencionado por meio de uma pesquisa na internet. A segunda maneira mais apontada pelos professores $(\mathrm{N}=18)$ foi o conhecimento do RD em um curso de formação de professores para o uso didático de tecnologias. No caso das disciplinas de Física e Química, o percentual de 
professores que disse ter conhecido o RD por meio de Pesquisa e de um curso foi exatamente 0 mesmo (33,33\%), como podemos observar na Tabela 4.

Tabela 4 - Como os professores encontraram o RD mencionado

\begin{tabular}{|c|c|c|c|c|c|c|c|}
\hline Como encontrou o RD mencionado & Ciências e Biologia & $\%$ & Física e Química & $\%$ & Matemática & $\%$ & Total \\
\hline Pesquisa & 16 & 51,61 & 5 & 33,33 & 18 & 51,43 & 39 \\
\hline Recomendação de um colega professor & 3 & 9,69 & 2 & 13,33 & 6 & 17,14 & 11 \\
\hline Curso de Formação de Professores & 6 & 19,35 & 5 & 33,33 & 7 & 20 & 18 \\
\hline Outra maneira & 6 & 19,35 & 3 & 20,01 & 4 & 11,43 & 13 \\
\hline Total & 31 & 100 & 15 & 100 & 35 & 100 & 81 \\
\hline
\end{tabular}

Fonte: $\mathrm{O}$ autor.

Os professores que mencionaram terem encontrado de "Outra maneira", especificaram que foi por meio de sugestões do livro didático ou apostilas, programas de televisão ou consultando materiais didáticos antigos como vídeos gravados em fitas VHS que estavam na escola.

Despertar o interesse ou motivar os alunos a estudarem o conteúdo foi a finalidade mais apontada pelos professores de todas as disciplinas. $O$ uso do RD durante o processo de ensino com o propósito de ensinar um novo conceito, revisar um conceito estudado anteriormente e permitir aos alunos participarem ativamente da aula foram as finalidades menos mencionadas, como observa-se na Tabela 5 a seguir.

Tabela 5- Principal finalidade de uso do RD

\begin{tabular}{|c|c|c|c|c|c|c|c|}
\hline Principal Finalidade de uso do RD mencionado & Ciências e Biologia & $\%$ & Física e Química & $\%$ & Matemática & $\%$ & Total \\
\hline $\begin{array}{l}\text { Despertar o interesse ou motivar os alunos a estudarem o } \\
\text { conteúdo. }\end{array}$ & 12 & 38,7 & 5 & 33,33 & 14 & 40 & 31 \\
\hline Ensinar um novo conceito. & 0 & 0 & 1 & 6,67 & 0 & 0 & 1 \\
\hline Fornecer informações complementares sobre o conceito estudado. & 9 & 29,03 & 1 & 6,67 & 8 & 22,86 & 18 \\
\hline Permitir aos alunos participarem ativamente da aula. & 1 & 3,23 & 2 & 13,33 & 2 & 5,71 & 5 \\
\hline $\begin{array}{l}\text { Oferecer aos alunos a possibilidade de rever a teoria por meio de } \\
\text { atividades práticas realizadas com o objeto. }\end{array}$ & 7 & 22,58 & 4 & 26,67 & 9 & 25,71 & 20 \\
\hline Total & 31 & 100 & 15 & 100 & 35 & 100 & 81 \\
\hline
\end{tabular}

Fonte: O autor.

A alternativa "outra" foi assinalada por professores que consideram que há mais de uma finalidade de uso do RD ou visualizaram outra finalidade, como resumir o conteúdo.

A Figura 2 mostra que a resolução de um exercício, referente ao RD utilizado em aula, é a atividade mais solicitada aos alunos pelos professores, mesmo por aqueles que ministram as 
disciplinas Ciências e Biologia. Nessa questão, os professores podiam mencionar mais de uma atividade que solicitam aos alunos.

Figura 2- Atividade solicitada

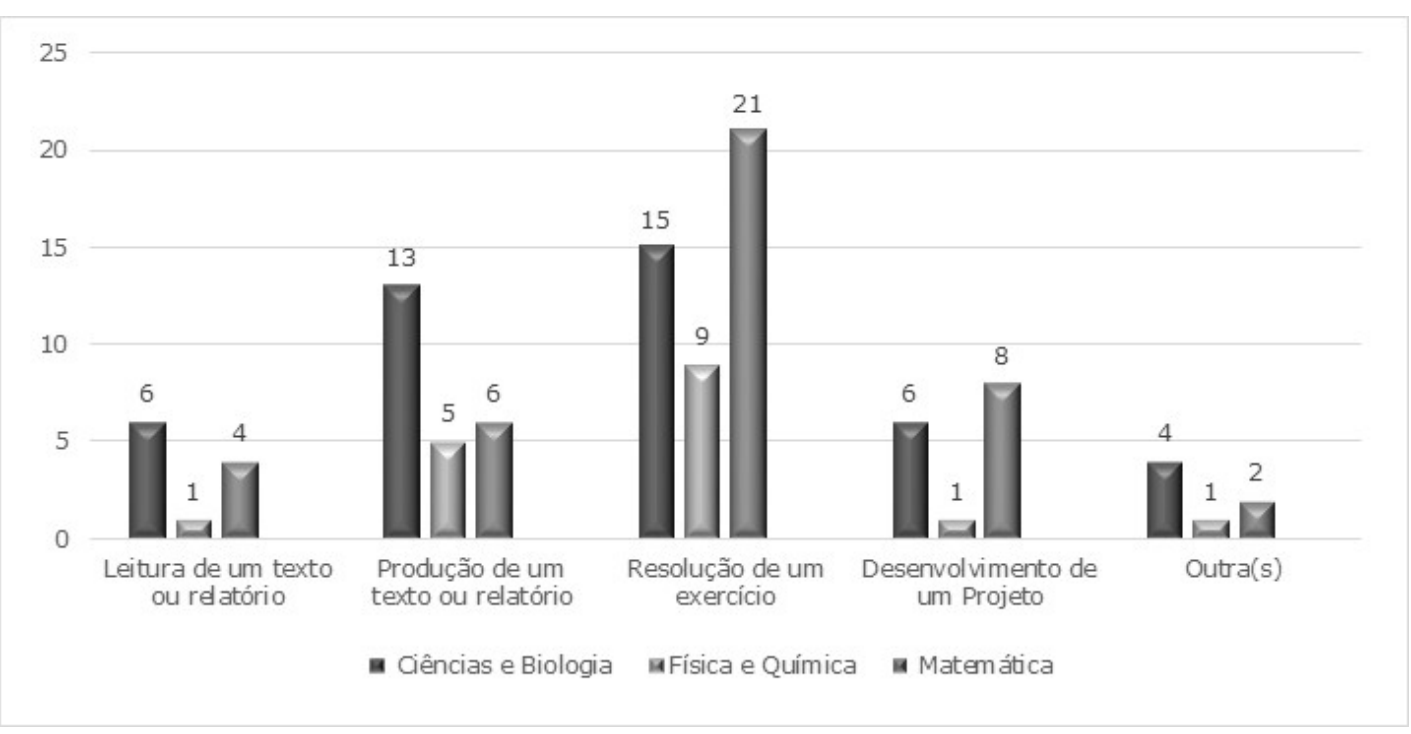

Fonte: O autor.

Os professores que responderam "outra(s)" mencionaram solicitar que os alunos desenvolvam, por exemplo, trabalhos que envolvem a construção de maquetes, organizem seminários utilizando os recursos apresentados, respondam a questionários no formato de palavras-cruzadas.

As práticas pedagógicas dos professores foram analisadas a partir das respostas que deram para as questões fechadas e abertas que buscaram investigar como exatamente eles utilizam os RD, as atividades que solicitam aos alunos.

Considerando a literatura, as práticas pedagógicas foram classificadas em duas categorias: prática instrucionista e prática construtivista. Definiu-se como instrucionista a prática que o professor apresenta o RD aos alunos, sem solicitar que o explore, e solicita atividades de memorização e reprodução de informações e como prática construtivista a que o professor não apenas apresenta o RD aos alunos, mas também demanda a sua exploração, de maneira que os alunos individualmente ou em grupo reflitam sobre o conteúdo trabalhado utilizando-se do RD.

Foram analisadas 35 práticas descritas por professores (13 de Ciências e Biologia, 12 de Física e Química e 10 de Matemática) com objetos encontrados nos portais mencionados anteriormente. $83 \%$ dos professores que relataram as práticas lecionam em escolas públicas, $11 \%$ em escolas privadas e $6 \%$ em ambas. Os dados mostram que as duas abordagens 
pedagógicas vêm sendo adotadas: 21 práticas foram classificadas como construtivistas e 14 como instrucionistas, conforme podemos observar na Figura 3 a seguir. Pode-se perceber, pela análise da Figura 3, que a disciplina que apresenta maior diferença entre o número de práticas instrucionistas e construtivistas é Matemática, em que a maioria das práticas ( 7 de 10), foi classificada como construtivistas.

Figura 3 - Práticas dos professores com RD

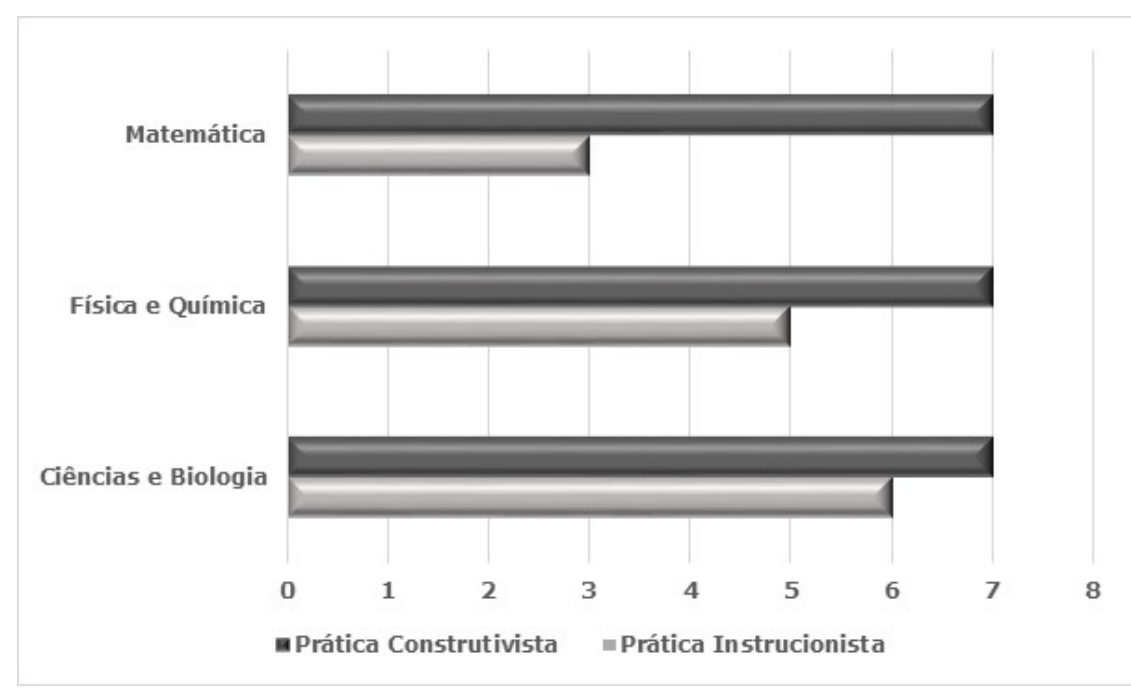

Fonte: O autor.

O Quadro 1 exemplifica 6 práticas (3 consideradas instrucionistas e 3 construtivistas), conforme a descrição apresentada pelos professores, referentes as disciplinas investigadas.

Quadro 1 - Exemplos de práticas relatadas com RD 


\begin{tabular}{|c|c|c|}
\hline Disciplina & Prática Instrucionista & Prática Construtivista \\
\hline Física e Química & $\begin{array}{l}\text { Assistir um vídeo sobre semicondutores com os alunos e } \\
\text { pedir para responderem um questionário a respeito. Após } \\
\text { terem respondido, discutir as respostas que deram às } \\
\text { questões e esclarecer as dúvidas. }\end{array}$ & $\begin{array}{l}\text { Trabalhar com os alunos o conteúdo sobre Geometria } \\
\text { molecular, solicitar que acessem uma simulação referente a esse } \\
\text { conteúdo, montem suas próprias estruturas e tirem suas próprias } \\
\text { conclusões. Discutir as conclusões que tiveram ou dúvidas } \\
\text { coletivamente. }\end{array}$ \\
\hline
\end{tabular}

Fonte: O autor.

O Anexo $2^{11}$ apresenta a relação de todas as práticas que foram analisadas, conforme a descrição apresentada pelos professores quando foram solicitados a relatar a estratégia de ensino que adotavam fazendo uso do RD que mencionaram.

\section{Discussão}

Os dados revelam que professores têm se apropriado de RD desenvolvidos por instituições governamentais como Secretarias Educacionais e o Ministério da Educação. Considera-se que isso é importante, uma vez que investimentos de recursos financeiros e humanos são necessários para, por exemplo, desenvolver RD e manter um portal educacional e espera-se, portanto, que sejam usados.

O portal Dia a Dia Educação, que é uma iniciativa da Secretaria Estadual de Educação do Paraná, aparece como sendo o mais citado. Deve-se considerar que $40 \%$ dos professores participantes do estudo lecionam no estado do Paraná. O Portal do Professor e o RIVED foram portais citados também.

O fato de vários professores terem mencionado os buscadores Google e Youtube lembra a necessidade de que RD disponibilizados nos portais institucionais (ex. Portal do Professor) estejam bem indexados, de maneira que os buscadores consigam encontrá-los. Entende-se que esses RD foram desenvolvidos ou selecionados para fins educacionais. Os buscadores como o Google facilitam a busca de conteúdos e são importantes ferramentas para localizar RD a partir do assunto a ser ensinado. Mas, é importante considerar que muitos dos RD, disponíveis na rede, sem vínculo com um determinado portal educacional ou que tenham passado por avaliação de outros professores, podem apresentar erros conceituais. É importante que os RD a

11 Os Quadros de cada uma das disciplinas foram criados especialmente para o presente estudo, a partir dos dados coletados dos professores, com o propósito de trazer todos os relatos referentes às práticas. 
serem utilizados no processo de ensino e aprendizagem tenham o seu conteúdo sempre previamente analisado, de maneira a identificar a viabilidade de utilizá-lo com os alunos.

A efetividade dos cursos de formação para que professores conheçam RD a serem utilizados no ensino também é comprovada pelos dados. Entende-se que a formação continuada, mesmo que a distância, com propósitos de ajudar no processo de integração das TDIC é importante. O acesso a informações, disponíveis na internet, não é suficiente para garantir que todos terão conhecimento sobre novos recursos que podem trazer contribuições ao ensino. Considera-se relevante que os cursos de formação de professores tenham como propósito também auxiliar os professores a adquirem a habilidade de saberem buscar novos recursos voltados aos seus objetivos educacionais.

O recurso "vídeo" é o RD que os professores mais utilizam. O estudo não investigou a razão específica da preferência pelo uso de cada um dos RD. As hipóteses são suas características, o potencial pedagógico e a facilidade de uso. O vídeo é um recurso que costuma despertar bastante 0 interesse pela sua possibilidade de associar imagens, textos e sons de uma forma dinâmica, representando muitas vezes situações ou cenários que correspondem à realidade ou, conforme lembra Bates (2015) difíceis de serem observados dependendo da natureza do fenômeno, ou sem equipamentos especiais, que muitas vezes são caros ou escassos. Entendese também que colocar um vídeo em funcionamento ou uso demanda ações consideradas operacionalmente mais simples ou conhecidas pela maioria das pessoas, diferentes das necessárias, por exemplo, para o uso de um software.

Um dos professores mencionou "'Na época da Universidade, eu tinha uma professora que trabalhava com filmes e de forma motivadora, então, busquei aplicar esse recurso em minhas aulas" (P77). Essa fala constata a tendência dos professores reproduzirem práticas que vivenciaram durante o seu processo de formação e os efeitos da modelação ou da aprendizagem a partir de modelos no comportamento docente. Conforme Bandura (1972 apud Costa, 2008), a modelação é um processo de aquisição ou modificação de comportamentos a partir de modelos. Docentes de cursos de formação podem ser modelos para futuros professores.

Softwares é um recurso usado principalmente pelos professores de Matemática. A hipótese é que eles mais facilmente visualizam como utilizá-los em função também de sua formação que pode ter contemplado o uso desse recurso. Uma outra hipótese, é que há uma quantidade maior de softwares para o ensino de Matemática, se comparado com a existente para as demais disciplinas.

No que se refere a principal finalidade do uso de RD, os resultados do presente estudo foram ao encontro de resultados de pesquisas anteriores como a de Carneiro e Passos (2014) e Kay e Knaack (2008) que constataram que professores consideram que eles são importantes principalmente para despertar o interesse ou motivar os alunos para os estudos. Despertar o interesse e motivar para os estudos foi a razão apontada por 38,2\% dos professores participantes. Embora apenas 1 professor tenha dito que o RD mencionado é usado com a finalidade de ensinar um novo conceito, os dados da Tabela 5 permitem constatar que professores estão usando RD com diferentes objetivos. A segunda finalidade mais apontada 
pelo conjunto de professores $(24,7 \%)$ foi a que o uso do RD oferece aos alunos uma possibilidade de rever a teoria por meio de atividades práticas que envolvem explorá-lo. Esse dado revela que professores têm percebido a importância dos alunos acessarem os RD e que esse momento de exploração, ou contato direto com o objeto, pode permitir aos alunos reverem conteúdos. Deve-se considerar que solicitou-se aos professores para informarem a principal finalidade com que usam o RD, o que significa que eles podem usá-lo com mais de um propósito, mas relataram apenas um deles.

A resolução de um exercício aparece como sendo a atividade que os professores mais solicitam aos alunos em todas as disciplinas investigadas. Devemos considerar que o tipo de atividade solicitada, a estratégia de ensino ou prática pedagógica relaciona-se com a natureza da disciplina e do conteúdo a ser ensinado, com objetivo pedagógico do professor, concepção de ensino e aprendizagem e como ele visualiza ensinar o conteúdo com um determinado recurso. De acordo com os estudos de Ribeiro (2010), Ministère de l' Éducation Nationale (2012), Ghavam (2013) e Henrique (2016), entende-se que muitos professores ainda não visualizam como adotar novas práticas ou propor novas atividades com as TDIC.

A análise das práticas pedagógicas de professores participantes do presente estudo revela que ambas as abordagens, instrucionistas e construtivistas ${ }^{12}$ estão sendo adotadas pelos professores de diferentes áreas do conhecimento. O fato de $60 \%$ das práticas envolverem a exploração das tecnologias também pelos alunos sinaliza que há professores que já conseguem visualizar e implementar estratégias de ensino que vão além de usar as TDIC simplesmente para expor ou transmitir os conteúdos, adotando TDIC em estratégias, as quais segundo Sigalés, 2008 (apud Coll, Mauri e Onrubia, 2010), voltam-se para uma concepção de ensino construtivista. Embora a maioria das práticas analisadas tenha sido considerada construtivistas, o percentual de práticas instrucionistas (40\%) pode ser considerado significativo. Esse dado vai ao encontro dos resultados obtidos nos estudos de Henrique (2016), Ribeiro (2010), Ministere De L' Éducation Nationale (2012) que constataram que muitos professores adotam as TDIC em estratégias que não envolvem a sua exploração pelos alunos, ou para realizar uma atividade que envolva analisar criticamente as informações veiculadas pelas mídias digitais.

A razão dos professores de Matemática serem os que mais têm adotado práticas que demandam a exploração de RD pelos alunos pode estar relacionada a natureza da disciplina, características dos conteúdos ensinados, formação dos professores, a qual pode ter envolvido o uso de recursos tecnológicos e Ihes permitem visualizar como utilizá-los mais facilmente, ou até mesmo a facilidade de acesso aos recursos tecnológicos. As condições de infraestrutura tecnológica, como a falta de computadores para acesso pelos alunos, também podem influenciar a escolha da estratégia de ensino. Ghavan (2013) nos lembra que as variáveis tempo e disposição física de recursos tecnológicos podem limitar a adoção de determinadas práticas pedagógicas. Considerando Carneiro e Passos (2014) pode-se dizer que ensinar com TDIC traz desafios aos professores. Entende-se que esses desafios referem-se também ao

12 Caracterizou-se no presente estudo a prática instrucionista como aquela que não demanda exploração da tecnologia pelo aluno ao contrário da construtivista. 
domínio dos diferentes tipos de conhecimentos exigidos do professor (do conteúdo, das estratégias de ensino e das tecnologias), apresentados pela abordagem TPCK de Mishra e Koehler (2006). O professor deve não apenas conhecer o conteúdo ou a matéria a ser ensinada, mas o potencial pedagógico de diferentes tecnologias, identificando como elas podem ajudar os alunos a superarem dificuldades, construírem ou ampliarem conhecimentos.

\section{Considerações Finais}

Os cursos de formação inicial e continuada de professores precisam trabalhar a contribuição de diferentes concepções de aprendizagem e abordagens pedagógicas para o ensino. Os docentes que atuam em cursos de licenciatura devem diversificar estratégias para que os licenciandos, futuros professores, mais facilmente visualizem possibilidades diferenciadas de ensinar. Cursos de formação continuada para o uso de TDIC no ensino também necessitam explorar o potencial pedagógico de diversos recursos, de maneira a ampliar o conhecimento pedagógico e tecnológico dos professores. Os professores têm que conhecer diferentes caminhos para atingir diferentes objetivos pedagógicos, como nos lembram Wilson, Shulman e Richert (1987).

Apesar de muitos professores terem relatado práticas com RD que foram consideradas instrucionistas, que envolvem apenas a exposição dos conteúdos e resolução de exercícios, é interessante notar, a partir dos dados do presente estudo, que as práticas pedagógicas com o uso de recursos tecnológicos estão mudando. Há professores que têm procurado adotar estratégias que envolvem não apenas o uso da TDIC pelo professor, mas também pelo aluno. 0 percentual de professores que apontaram fazer uso de práticas construtivistas é alto (60\%) e sinaliza que os professores, provavelmente em função da ampliação do acesso as TDIC ou formação que envolve o uso e tecnologias, estão indo além de fazer uso dos RD apenas para expor conteúdos. Isso é bastante positivo, uma vez que adotar metodologias de ensino ativas é uma necessidade colocada para os professores, para o processo de ensino e aprendizagem, como lembra Valente, Almeida e Geraldini (2017).

Entende-se como importante ressaltar que, cada uma das teorias da aprendizagem e das abordagens pedagógicas trazem importantes contribuições ao processo de ensinar. Moran (2018) faz uma analogia entre o ensino e a alimentação saudável. Para o autor, assim como uma alimentação saudável deve ser resultado de uma diversidade de alimentos combinados de diferentes formas, objetivos de aprendizagem devem ser atingidos a partir de diferentes estratégias. Nas palavras do autor: "na educação formal, há muitas combinações possíveis, com variações imensas na aplicação e resultados, que vamos experimentando de forma dinâmica e constante, reavaliando-as e reinventando-as de acordo com a conveniência para obter os resultados desejados" (MORAN, 2018, p.13). Embora tenha-se para fins de análise de dados, classificado as abordagens em instrucionistas e construtivistas, isso não significa compreender que a abordagem instrucionista não contribui para a aprendizagem. Deve-se sempre considerar o que os alunos precisam aprender e que mesmo as aulas expositivas podem favorecer a construção de conhecimentos. De acordo com Coll (2004, p. 125-126): 
para a concepção construtivista do ensino e da aprendizagem, a metodologia didática eficaz é a regida pelo princípio de ajuste da ajuda pedagógica e que, de acordo com tal princípio, concretiza-se com métodos diferentes conforme os casos e circunstâncias. Portanto, dessa perspectiva, os "métodos de ensino" não são, em princípio, aceitáveis ou recusáveis por si mesmos e em termos absolutos, mas devem ser valorizados em função do seu maior ou menor grau de ajuste às necessidades do processo de construção que os alunos realizam.

Outro aspecto importante a ser lembrado, é que os professores do estudo foram convidados a relatarem uma estratégia de ensino relacionada ao uso que faziam de um determinado objeto ou RD que foi solicitado que mencionassem, e que isso não permite afirmar que não façam uso de outras estratégias e objetos. Mas sim que, para fins de participação no estudo, priorizaram o relato de uma determinada estratégia.

Entre as contribuições do presente estudo está a proposta de compartilhar com pesquisadores, professores e formadores uma relação de sites, recursos digitais disponíveis para uso gratuito (Anexo 1) e também relatos de práticas pedagógicas que envolvem o uso de $\mathrm{RD}$ (Anexo 2). Entende-se que ainda há professores que não usam determinados recursos porque não os conhecem ou não visualizam como utilizá-los, que programas de formação de professores para o uso de TDIC, muitas vezes, são planejados sem considerar o que os professores já sabem, quais e como determinados RD vem sendo utilizados didaticamente.

Os resultados aqui encontrados não podem ser generalizados. Considera-se importante que outros estudos envolvendo metodologias de análise qualitativa, por exemplo, com as técnicas de coleta de dados por meio de entrevista e observação, sejam desenvolvidos. A observação de aulas com RD pode trazer mais informações e melhor caracterizar as abordagens ou metodologias de ensino com o uso de TDIC. Ampliar a compreensão de como as TDIC estão sendo usadas didaticamente e compartilhar práticas pedagógicas são importantes caminhos rumo à melhor integração das TDIC ao processo de ensinar e aprender.

\section{Agradecimento}

A autora agradece à CAPES (Processo BEX 17.818/12-5), aos professores que participaram e/ou divulgaram o estudo, a todos que colaboraram de alguma forma para a sua realização, em especial ao Prof. Dr. Jacques Ginestié, Profa. Dra. Pascale Brandt-Pomares- Aix-Marseille Université/França e Profa. Dra. Roberta Gurgel Azzi-Teoria Social Cognitiva/Brasil.

\section{Referências}

BARDIN, L. Análise de conteúdo. Lisboa: Edições 70, 1995.

BATES, A. W. T. Pedagogical differences between media. Teaching in a digital age: guidelines for teaching and learning. Tony Bates Associates Ltd, 2015, Disponível em: <http://www.tonybates.ca/ teaching-in-a-digital-age>. Acesso em: 03 dez. 2018. p.227-261.

BEHAR, P.A. Modelos pedagógicos em Educação a Distância. In: BEHAR, P.A. (Orgs.). Modelos

Pedagógicos em Educação a Distância. Porto Alegre: Artmed, 2009. p.15-32. 
BELLICO DA COSTA, A.E. Modelação. In: BANDURA, A.; AZZI, R.; POLYDORO, S. A. J. e col. Teoria social cognitiva: conceitos básicos. Porto Alegre: Artmed, 2008. p.123-148.

BRASIL. Ministério da Ciência e Tecnologia e Ministério da Educação e Cultura. Edital de seleção No. 1/2007. Chamada pública para apoio financeiro à produção de conteúdos educacionais digitais multimídia. Ministério da Ciência e Tecnologia e Ministério da Educação. Disponível em <http://portal.mec.gov.br/ arquivos/pdf/conteudosdigitais.pdf>. Acesso em: 03 dez. 2018.

BRASIL. Ministério da Educação. Portal do Professor. Disponível em: < http:// portaldoprofessor.mec.gov.br/index.html>. Acesso em: 20 nov. 2018.

BRASIL. Ministério da Educação. Secretaria de Educação a Distância. Secretaria da Educação Básica. RIVED. Rede Interativa Virtual de Educação. Disponível em: <http://rived.mec.gov.br>. Acesso em: 20 nov. 2018

CARNEIRO, R.F.; PASSOS, C.L.B. A utilização das Tecnologias de Informação e Comunicação na aulas de Matemática: limites e possibilidades. Revista Eletrônica de Educação. v.8, n.2, p.101-119, 2014.

COLL, C.; MAURI, T. ; ONRUBIA,T. A incorporação das tecnologias da informação e da comunicação na educação: do projeto técnico-pedagógico às práticas de uso. In: Coll, C.; Monero, C. e cols. Psicologia da Educação Virtual. Aprender e Ensinar com as Novas Tecnologias da Informação e Comunicação. Trad. Naila Freitas. Porto Alegre : Artmed, 2010. p.66 - 93.

COLL, C. Construtivismo e educação: a concepção construtivista do ensino e da aprendizagem. In: COLL, C.; MARCHESI, A.; PALACIOS, J. Desenvolvimento Psicológico e educação. Psicologia da Educação Escolar. v.2. 2a. Ed. Porto Alegre: Artmed, 2004. p.107-127.

COLL, C. As contribuições da Psicologia para a Educação: Teoria Genética e Aprendizagem Escolar. In: Piaget e a escola de Genebra. Leite, L. B (Org). Editora Cortez: São Paulo, 1992.

GHAVAM, P-L. Le numérique dans I'EPLE : Quelques réflexions inspirées par l'exemple landais. Revue Trimestrielle de l'Association Française des Acteurs de l'Éducation. Vers quelles organisations scolaires à l'ère du numérique ? Admistration \& Éducation, 3, 2013, p. 73-80.

HENRIQUE, A.R.P. Escola particular de Juiz de Fora: o uso das TIC na prática docente do 90 ano do Ensino Fundamental. XIII Evidosol e X CILTEC Online, jun., 2016, p.1-5.

INSTITUTO DE EVALUACIÓN Y ASESORAMIENTO EDUCATIVO, NETURITY Y FUNDACIÓN GERMÁN SÁNCHEZ RUIPÉREZ2(2007). Las Tecnologías de la Información y de la Comunicación en la Educación. Informe sobre la implantación y el uso de las TIC en los centros docentes de educación primaria y secundaria (curso 2005-2006). Madrid. Disponível em: < http://www.oei.es/tic/TICCD.pdf > Acesso em: 02 dez.2018.

KAY, R. H.; KNAACK, L. Teacher evaluation of learning objects in middle and secondary school classrooms, 2007. Disponível em: < http://faculty,uoit.ca/kay/papers/LOES_Teacher_2007.doc >, Acesso em: 05 mai. 2013

KAY, R. H.; KNAACK, L. An examination of the impact of learning objects in secondary school. Journal of Computer Assisted Learning, 24, 2008, p.447-461.

KAY, R. H. ; KNAACK, L. Assessing learning, quality and engagement in learning objects: The Learning Object Evaluation Scale for Students (LOES-S). Educational Technology Research and Development. $57,2009,147-168$

KRAWCZYK, N. O ensino médio no Brasil. São Paulo: Ação Educativa, 2009.

MESQUITA, D., PIVA Jr., D., GARA, E.B.M. As principais abordagens pedagógicas e os ambientes virtuais de aprendizagem. Ambiente Virtual de Aprendizagem. Conceitos, Normas, Procedimentos e Práticas Pedagógicas no Ensino a Distância. São Paulo: Érica, 2014. p.65-76. 
MINISTERE DE L' ÉDUCATION NATIONALE. Rapport Enquête PROFETIC. 14 juin 2012. France: Ministère de I'Éducation Nationale, 2012. Disponível em : <http://cache.media.eduscol.education.fr/file/ ETIC_et_PROFETIC/88/0/profetic-2012-rapport_221880.pdf>. Acesso em: 02 dez. 2018.

MISHRA, P.; KOEHLER, M. J. Technological Pedagogical Content Knowledge: A Framework for Teacher Knowledge. Teachers College Record. v. 108, n.6, 2006, p. 1017-1054.

MORAN, J. Metodologias ativas para uma aprendizagem mais profunda. In: BACICH, L.; MORAN, J. Metodologias ativas para uma educação inovadora. Uma abordagem teórico-prática. Porto Alegre: Penso, 2018, p. 1-25.

OLIVEIRA, M. K. Desenvolvimento e aprendizado. In OLIVEIRA, M. K.Vygotsky. Aprendizado e desenvolvimento. Um processo sócio-histórico. (4ª Ed.) São Paulo, Scipione, 2001.p.52-72.

RATOMPOMALALA, H., BRUILLARD, E., \& RAZAFIMBELO, J. Quelle formation en TIC, quelles utilisations en classe des professeurs de Physique et Chimie ? Une étude en France. RDST-Recherches en didactique des Sciences et des Technologies. TIC et apprentissage des Sciences: promesses et usages, 6 , 2012, p. 53-85.

RIBEIRO, A. L. O papel da escola básica como agência promotora do letramentto digital. E-Hum, Belo Horizonte, 3 (3), 2010, p.1-15.

SMITH, R.S. Guidelines for authors of learning objects. Austin: NCM: The New Media Consortium, Mcgraw-Hill Education, 2004.

SHULMAN, L.S. Those Who Understand: Knowledge Growth in Teaching. Educational Researcher, Vol. 15, No. 2.Feb., 1986, p. 4-14.

VALENTE, J.A. ; ALMEIRA, M.E.B. ; GERALDINE, A.F.S. Metodologias ativas: das concepções às práticas em diferentes níveis de ensino. Revista Diálogo Educacional. Curitiba.v.17, n. 52, abr./jun., 2017, p. 455-478.

WILSON, S.M.; SHULMAN, L.S.; RICHERT, A.L. 150 different ways' of knowing: representations of knowledge in teaching. In: CALDERHEAD, J (Org.). Exploring Teachers' Thinking. Cassel Educational Limited, 1987, p. 104-124.

Recebido em março de 2017.

Aprovado para publicação em dezembro de 2018.

\section{Cacilda Encarnação Augusto Alvarenga}

Curso de Graduação em Pedagogia - Centro Universitário da Fundação Hermínio Ometto - FHO, Brasil, cacilda.alvarenga@gmail.com 


\section{ANEXO 1}

Quadro 2 - Recursos mencionados pelos professores

\begin{tabular}{|c|c|c|c|}
\hline $\begin{array}{l}\text { Disciplin } \\
\quad \text { a }\end{array}$ & $\begin{array}{l}\text { Ano e Nível de } \\
\text { Ensino }\end{array}$ & $\begin{array}{l}\text { Nome do } \\
\text { recurso }\end{array}$ & Endereço eletrônico \\
\hline $\begin{array}{l}\text { Ciências e } \\
\text { Biologia }\end{array}$ & $\begin{array}{l}70 \text { ano Ensino } \\
\text { Fundamental (E.F) }\end{array}$ & $\begin{array}{l}\text { Animação } \\
\text { sobre o } \\
\text { Sistema } \\
\text { Respiratório }\end{array}$ & $\begin{array}{l}\text { http://www.aticaeducacional.com.br/htdocs/ } \\
\text { atividades/sist_resp/atv1.htm }\end{array}$ \\
\hline $\begin{array}{l}\text { Ciências e } \\
\text { Biologia }\end{array}$ & $6^{\circ}$ ano do E.F. & $\begin{array}{l}\text { Animação } \\
\text { Cadeia } \\
\text { Alimentar } \\
\text { em } \\
\text { Desequilíbri } \\
\text { o Ambiental }\end{array}$ & $\begin{array}{l}\text { http://www.educadores.diaadia.pr.gov.br/arquivos/ } \\
\text { File/agosto2011/ciencias_simuladores/ } \\
\text { 36ciclo_natural.swf }\end{array}$ \\
\hline $\begin{array}{l}\text { Ciências e } \\
\text { Biologia }\end{array}$ & $6^{\circ}$ ano do E.F. & $\begin{array}{l}\text { Vídeo } \\
\text { Floresta } \\
\text { Amazônica } \\
\text { - } \\
\text { Queimadas } \\
\text { Seca }\end{array}$ & http://www.educacao.video.pr.gov.br/?video=9820 \\
\hline $\begin{array}{l}\text { Ciências e } \\
\text { Biologia }\end{array}$ & $6^{\circ}$ ano do E.F. & $\begin{array}{l}\text { Vídeo sobre } \\
\text { o Ciclo da } \\
\text { água }\end{array}$ & http://www.educacao.video.pr.gov.br/?video=9649 \\
\hline $\begin{array}{l}\text { Ciências e } \\
\text { Biologia }\end{array}$ & $\begin{array}{l}10 \text { ao } 30 \text { ano do } \\
\text { Ensino Médio (E.M) }\end{array}$ & $\begin{array}{l}\text { Vídeo Ilha } \\
\text { das flores }\end{array}$ & https://www.youtube.com/watch?v=Hh6ra-18mY8 \\
\hline $\begin{array}{l}\text { Ciências e } \\
\text { Biologia }\end{array}$ & $\begin{array}{l}6^{\circ} \text { ao } 9^{\circ} \text { ano do E.F., } \\
1^{0} \text { ao } 3^{\circ} \text { anos do E.M. }\end{array}$ & $\begin{array}{l}\text { Vídeos } \\
\text { biodiversida } \\
\text { de }\end{array}$ & $\begin{array}{l}\text { http://www.educadores.diaadia.pr.gov.br/ } \\
\text { search.php?query=biodiversidade }\end{array}$ \\
\hline $\begin{array}{l}\text { Ciências e } \\
\text { Biologia }\end{array}$ & $6^{\circ}$ ao 90 ano do E.F. & $\begin{array}{l}\text { Atividades } \\
\text { online } \\
\text { AticaEducac } \\
\text { ional }\end{array}$ & $\begin{array}{l}\text { http://www.aticaeducacional.com.br/htdocs/ } \\
\text { atividades/atividades.aspx }\end{array}$ \\
\hline $\begin{array}{l}\text { Ciências e } \\
\text { Biologia }\end{array}$ & $5^{\circ}$ ao 9 a ano do E.F. & $\begin{array}{l}\text { Conteúdos } \\
\text { RachaCuca }\end{array}$ & http://rachacuca.com.br/educacao/biologia/ \\
\hline $\begin{array}{l}\text { Ciências e } \\
\text { Biologia }\end{array}$ & $\begin{array}{l}1^{\circ} \text { ao } 3^{\circ} \text { anos do } \mathrm{E} \text {. } \\
\mathrm{M} \text {. }\end{array}$ & $\begin{array}{l}\text { Imagens } \\
\text { Biologia }\end{array}$ & $\begin{array}{l}\text { http://www.biologia.seed.pr.gov.br/modules/galeria/ } \\
\text { listaEventos.php }\end{array}$ \\
\hline $\begin{array}{l}\text { Ciências e } \\
\text { Biologia }\end{array}$ & $\begin{array}{l}6^{\circ} \text { ao } 9^{\circ} \text { ano do E. F. e } \\
1^{0} \text { ano do E. M. }\end{array}$ & $\begin{array}{l}\text { Imagens } \\
\text { Google }\end{array}$ & https://www.google.com/ \\
\hline
\end{tabular}




\begin{tabular}{|c|c|c|c|}
\hline $\begin{array}{l}\text { Ciências e } \\
\text { Biologia }\end{array}$ & $\begin{array}{l}5^{\circ} \text { ao } 9 \text { a ano do } E . F . \\
\text { e } 1^{\circ} \text { ao } 3^{\circ} \text { ano do } E \text {. } \\
\text { M. }\end{array}$ & $\begin{array}{l}\text { Vídeos } \\
\text { Youtube }\end{array}$ & https://www.youtube.com/ \\
\hline $\begin{array}{l}\text { Ciências e } \\
\text { Biologia }\end{array}$ & $\begin{array}{l}5^{\circ} \text { ao } 9 \text { a ano do E. F. } \\
\text { e } 1^{0} \text { ao } 3^{\circ} \text { ano do E.M. }\end{array}$ & $\begin{array}{l}\text { Vídeos } \\
\text { Portal do } \\
\text { Professor }\end{array}$ & http://portaldoprofessor.mec.gov.br/recursos.html \\
\hline $\begin{array}{l}\text { Ciências e } \\
\text { Biologia }\end{array}$ & $6^{\circ}$ ao $9^{\circ}$ ano do E. F. & $\begin{array}{l}\text { Recursos } \\
\text { didáticos } \\
\text { multimídia } \\
\text { "diadia } \\
\text { educadores } \\
\text { " }\end{array}$ & $\begin{array}{l}\text { http://www.educadores.diaadia.pr.gov.br/modules/ } \\
\text { conteudo/conteudo.php?conteudo }=3\end{array}$ \\
\hline $\begin{array}{l}\text { Ciências e } \\
\text { Biologia }\end{array}$ & $\begin{array}{l}5^{\circ} \text { ao } 90 \text { anos do E. F. } \\
\text { e } 1^{\circ} \text { ao } 3^{\circ} \text { anos do } E \text {. } \\
\text { M. }\end{array}$ & $\begin{array}{l}\text { Objetos de } \\
\text { aprendizage } \\
\text { m RIVED }\end{array}$ & http://rived.mec.gov.br/ \\
\hline $\begin{array}{l}\text { Física e } \\
\text { Química }\end{array}$ & 30 ano do $\mathrm{E} . \mathrm{M}$. & $\begin{array}{l}\text { Vídeo sobre } \\
\text { semicondut } \\
\text { ores }\end{array}$ & $\begin{array}{l}\text { https://www.youtube.com/watch? } \\
\text { v=tIQdOps2KKQ\&feature=youtube }\end{array}$ \\
\hline $\begin{array}{l}\text { Física e } \\
\text { Química }\end{array}$ & $1^{0}$ ao $3^{\circ}$ anos do E. M. & $\begin{array}{l}\text { Exercícios, } \\
\text { simulados e } \\
\text { jogos } \\
\text { Sofísica }\end{array}$ & http://www.sofisica.com.br/ \\
\hline $\begin{array}{l}\text { Física e } \\
\text { Química }\end{array}$ & $1^{\circ}$ e $3^{\circ}$ anos do E.M. & $\begin{array}{l}\text { Simulação } \\
\text { de } \\
\text { Geometria } \\
\text { molecular }\end{array}$ & $\begin{array}{l}\text { https://phet.colorado.edu/pt/simulation/molecule- } \\
\text { shapes-basics }\end{array}$ \\
\hline $\begin{array}{l}\text { Física e } \\
\text { Química }\end{array}$ & $1^{\circ}$ e $3^{\circ}$ anos do E.M. & $\begin{array}{l}\text { Simulação } \\
\text { de } \\
\text { construção } \\
\text { de } \\
\text { moléculas }\end{array}$ & $\begin{array}{l}\text { http://www.quimica.seed.pr.gov.br/modules/links/ } \\
\text { uploads/1/147900constmoleculas_lapeq.swf }\end{array}$ \\
\hline $\begin{array}{l}\text { Física e } \\
\text { Química }\end{array}$ & $1^{\circ}$ e $3^{\circ}$ anos do E.M. & $\begin{array}{l}\text { Vídeo sobre } \\
\text { átomos }\end{array}$ & $\begin{array}{l}\text { http://www.educadores.diaadia.pr.gov.br/modules/ } \\
\text { video/showVideo.php?video=14159 }\end{array}$ \\
\hline $\begin{array}{l}\text { Física e } \\
\text { Química }\end{array}$ & $\begin{array}{l}90 \text { ano do E. F. e } 10 \\
\text { ano do E. M. }\end{array}$ & $\begin{array}{l}\text { Tabela } \\
\text { periódica }\end{array}$ & http://nautilus.fis.uc.pt/cec/jogostp/ \\
\hline $\begin{array}{l}\text { Física e } \\
\text { Química }\end{array}$ & $1^{\circ}$ e $3^{\circ}$ anos $\mathrm{E} . \mathrm{M}$. & $\begin{array}{l}\text { Vídeo sobre } \\
\text { o processo } \\
\text { siderúrgico }\end{array}$ & $\begin{array}{l}\text { https://www.youtube.com/watch? } \\
\text { v=LN6G4gaZUPw\&list=PL5FD1D96083DA9211 }\end{array}$ \\
\hline $\begin{array}{l}\text { Física e } \\
\text { Química }\end{array}$ & $1^{\circ}$ ao $3^{\circ}$ ano do E. M. & $\begin{array}{l}\text { Animações } \\
\text { "a graça da } \\
\text { Química" }\end{array}$ & $\begin{array}{l}\text { http://www.agracadaquimica.com.br/index.php? } \\
\text { acao=simula\& }=5\end{array}$ \\
\hline $\begin{array}{l}\text { Física e } \\
\text { Química }\end{array}$ & $\begin{array}{l}6^{\circ} \text { ao } 9^{\circ} \text { ano do E.F. e } \\
1^{\circ} \text { ano do E. M. }\end{array}$ & $\begin{array}{l}\text { Imagens } \\
\text { Google }\end{array}$ & https://www.google.com/ \\
\hline
\end{tabular}




\begin{tabular}{|c|c|c|c|}
\hline $\begin{array}{l}\text { Física e } \\
\text { Química }\end{array}$ & $\begin{array}{l}5^{\circ} \text { ao } 9 \text { a ano do E.F. e } \\
1^{\circ} \text { ao } 3^{\circ} \text { ano do E.M. }\end{array}$ & $\begin{array}{l}\text { Vídeos } \\
\text { Youtube e } \\
\text { Portal do } \\
\text { Professor }\end{array}$ & https://www.youtube.com/ \\
\hline $\begin{array}{l}\text { Física e } \\
\text { Química }\end{array}$ & $\begin{array}{l}5^{\circ} \text { ao } 9 \text { a ano do E. F. e } \\
1^{\circ} \text { ao } 3^{\circ} \text { ano do E.M. }\end{array}$ & $\begin{array}{l}\text { Portal do } \\
\text { Professor }\end{array}$ & http://portaldoprofessor.mec.gov.br/recursos.html \\
\hline $\begin{array}{l}\text { Física e } \\
\text { Química }\end{array}$ & $\begin{array}{l}6^{\circ} \text { ao } 9^{\circ} \text { ano do } \mathrm{E} \text {. } \\
\mathrm{F} \text {. }\end{array}$ & $\begin{array}{l}\text { Recursos } \\
\text { didáticos } \\
\text { multimídia } \\
\text { "diadia } \\
\text { educadores } \\
\text { " }\end{array}$ & $\begin{array}{l}\text { http://www.educadores.diaadia.pr.gov.br/modules/ } \\
\text { conteudo/conteudo.php?conteudo=3 }\end{array}$ \\
\hline $\begin{array}{l}\text { Física e } \\
\text { Química }\end{array}$ & $\begin{array}{l}\text { 5o ao } 90 \text { anos do E. F. } \\
\text { e } 1^{\circ} \text { ao } 3^{\circ} \text { anos do } E \text {. } \\
\text { M. }\end{array}$ & $\begin{array}{l}\text { Objetos de } \\
\text { aprendizage } \\
\text { m RIVED }\end{array}$ & http://rived.mec.gov.br/ \\
\hline $\begin{array}{l}\text { Matemátic } \\
\text { a }\end{array}$ & $5^{\circ}$ ao $9^{\circ}$ ano do E. F. & $\begin{array}{l}\text { Vídeo } \\
\text { Matemática } \\
\text { no cotidiano }\end{array}$ & https://www.youtube.com/watch?v=8dIKHJOOEtM \\
\hline $\begin{array}{l}\text { Matemátic } \\
\text { a }\end{array}$ & $8^{\circ}$ ao $9^{\circ}$ ano do E.F. & $\begin{array}{l}\text { Vídeo sobre } \\
\text { funções } \\
\text { polinomiais } \\
\text { e suas } \\
\text { raízes }\end{array}$ & $\begin{array}{l}\text { http://www.matematica.seed.pr.gov.br/modules/ } \\
\text { video/showVideo.php?video }=17570\end{array}$ \\
\hline $\begin{array}{l}\text { Matemátic } \\
\text { a }\end{array}$ & $9^{\circ}$ ano do E.F. & $\begin{array}{l}\text { Jogo das } \\
\text { Coordenada } \\
\text { s } \\
\text { Cartesianas }\end{array}$ & $\begin{array}{l}\text { http://www.oswego.org/ocsd-web/games/billybug2/ } \\
\text { bug2.html }\end{array}$ \\
\hline $\begin{array}{l}\text { Matemátic } \\
\text { a }\end{array}$ & $\begin{array}{l}8^{\circ} \text { e } 9^{\circ} \text { anos do E.F. e } \\
1^{\circ} \text { ao } 3^{\circ} \text { anos do } E . \\
\text { M. }\end{array}$ & $\begin{array}{l}\text { Software } \\
\text { Geogebra }\end{array}$ & http://www.geogebra.org/download \\
\hline $\begin{array}{l}\text { Matemátic } \\
\text { a }\end{array}$ & $\begin{array}{l}6^{\circ} \text { e } 70 \text { anos do E.F. e } \\
1^{0} \text { ao } 3 \circ \text { ano do E.M. }\end{array}$ & $\begin{array}{l}\text { Simuladore } \\
\text { s e } \\
\text { animações }\end{array}$ & $\begin{array}{l}\text { http://www.matematica.seed.pr.gov.br/modules/ } \\
\text { links/links.php?ini=R\&categoria }=34\end{array}$ \\
\hline $\begin{array}{l}\text { Matemátic } \\
\text { a }\end{array}$ & 90 ano do E. F. & $\begin{array}{l}\text { Softwares } \\
\text { de } \\
\text { Matemática } \\
\text { Dinâmica } \\
\text { Mathematic } \\
\text { s }\end{array}$ & http://microsoft-mathematics.br.uptodown.com/ \\
\hline $\begin{array}{l}\text { Matemátic } \\
\text { a }\end{array}$ & $\begin{array}{l}50 \text { ao } 9 \text { o ano do } \mathrm{E} \text {. } \\
\text { F. }\end{array}$ & $\begin{array}{l}\text { Vídeos } \\
\text { sobre } \\
\text { temas } \\
\text { estudados } \\
\text { em } \\
\text { Matemática } \\
\text { disponíveis } \\
\text { no Youtube }\end{array}$ & https://www.youtube.com/ \\
\hline
\end{tabular}




\begin{tabular}{|c|c|c|c|}
\hline $\begin{array}{l}\text { Matemátic } \\
\text { a }\end{array}$ & 60 ao 9 o ano do E. F. & $\begin{array}{l}\text { Exercícios } \\
\text { Somatemáti } \\
\text { ca }\end{array}$ & http://www.somatematica.com.br/soexercicios.php \\
\hline $\begin{array}{l}\text { Matemátic } \\
\text { a }\end{array}$ & 60 ao 9 o ano do E. F. & $\begin{array}{l}\text { Exercícios } \\
\text { Brasil } \\
\text { Escola }\end{array}$ & $\begin{array}{l}\text { http://exercicios.brasilescola.com/exercicios- } \\
\text { matematica/ }\end{array}$ \\
\hline $\begin{array}{l}\text { Matemátic } \\
\text { a }\end{array}$ & $\begin{array}{l}60 \text { ao } 9 \text { o ano do } \mathrm{E} \text {. } \\
\text { F. }\end{array}$ & $\begin{array}{l}\text { Recursos } \\
\text { didáticos } \\
\text { multimídia } \\
\text { "diadia } \\
\text { educadores } \\
\text { " }\end{array}$ & $\begin{array}{l}\text { http://www.educadores.diaadia.pr.gov.br/modules/ } \\
\text { conteudo/conteudo.php?conteudo }=3\end{array}$ \\
\hline $\begin{array}{l}\text { Matemátic } \\
\text { a }\end{array}$ & $\begin{array}{l}60 \text { ao } 90 \text { ano do } \mathrm{E} \text {. } \\
\text { F. et } 1^{\circ} \text { ao } 3^{\circ} \text { ano do } \\
\text { E. M. }\end{array}$ & $\begin{array}{l}\text { Objetos de } \\
\text { aprendizage } \\
\text { m RIVED }\end{array}$ & http://rived.mec.gov.br/ \\
\hline
\end{tabular}

Fonte: O autor 


\section{ANEXO 2}

Quadro 2 - Práticas pedagógicas relatadas pelos Professores de Ciências e Biologia13

\begin{tabular}{|c|c|}
\hline Prática Instrucionista & Prática Construtivista \\
\hline $\begin{array}{l}\text { Mostrar o video ao final do conteúdo trabalhado. Sugere-se antes de } \\
\text { apresentá-lo chamara atenção dos alunos para a riqueza do texto e da } \\
\text { narração. Ao final, abrir uma discussão com a sala sobre o que foi mostrado e } \\
\text { fazer um rápido apanhado sobre a mensagem do filme para garantir que foi } \\
\text { entendido. Solicitar que os alunos redijam um texto (dissertação } \\
\text { argumentativa) sobre o assunto "lixo". Os alunos, geralmente, questionam: } \\
\text { "De quando é esse filme? Se isso é realmente verdade? Se ainda persiste o } \\
\text { problema? }\end{array}$ & $\begin{array}{l}\text { Apresentar a animação aos alunos como um problema que deve ser resolvido, para se } \\
\text { chegar ao equilíbrio ecológico da regiẫo apresentada. Sugere-se que seja trabalhada } \\
\text { coletivamente na aula para discutir problemas apresentados, por meio da animação, e } \\
\text { propor novas ações que poderiam ser tomadas na resolução dos problemas. Após o } \\
\text { trabalho com a animação pode-se solicitar aos alunos a leitura de um texto ou relatório e } \\
\text { em seguida a resolução de um exercício. }\end{array}$ \\
\hline $\begin{array}{l}\text { Elaborar algumas questões relacionadas ao conteúdo apresentado no vídeo } \\
\text { que possam orientar a atenção do aluno para aspectos que o professor } \\
\text { considera importantes. Mostrar o video para os alunos e retomar as questões } \\
\text { propostas no início. Solicitar a produção de um texto ou o desenvolvimento de } \\
\text { um Projeto. }\end{array}$ & $\begin{array}{l}\text { Apresentar o vídeo e indagar os alunos a respeito do assunto tratado, solicitar que eles } \\
\text { relatem situaçóes vivenciadas no seu dia a dia e realizem a resolução de um exercício } \\
\text { relacionado aos conceitos trabalhados. Esse exercíio pode ser responder questôes no } \\
\text { formato de um questionário ou uma cruzadinha, palavras cruzadas. }\end{array}$ \\
\hline $\begin{array}{l}\text { Apresentar a imagem ao aluno antes, durante ou depois da explicação do } \\
\text { conteúdo a ela relacionado. Solicitar aos alunos a resolução de um exercício, } \\
\text { leitura ou produção de um texto referente ao conteúdo ilustrado ou } \\
\text { exemplificado pela imagem. }\end{array}$ & $\begin{array}{l}\text { Orientar os alunos em relação ao conteúdo ou atividade que devem acessar para iniciar o } \\
\text { estudo de um determinado conceito ou assunto ou para revisá-los. A atividade pode } \\
\text { envolver a resolução de um exercício, a leitura ou produção de um texto ou relatório, bem } \\
\text { como o desenvolvimento de um Projeto. }\end{array}$ \\
\hline \multirow[t]{2}{*}{$\begin{array}{l}\text { Antes de mostrar o video para os alunos, apresentar algumas questões } \\
\text { relacionadas ao seu conteúdo de forma a direcionar a atenção deles ao } \\
\text { assistirem. Orientá-los a prestarem atenção no vídeo. Após mostrar o vídeo, } \\
\text { solicitar que respondam oralmente as questões apresentadas inicialmente. A } \\
\text { partir das respostas, trabalhar o(s) conceito(s) presentes no video. Solicitar } \\
\text { que os alunos resolvam exercíios ou desenvolvam atividades relacionadas ao } \\
\text { que foi ensinado. O professor pode utilizar-se do vídeo durante a explicação } \\
\text { do conteúdo, chamando a atenção do aluno para as imagens, o que é é } \\
\text { mostrado. Essa é uma forma de provar também a teoria. }\end{array}$} & $\begin{array}{l}\text { Apresentar o objeto relacionado ao tema ou solicitar que os alunos o acessem. Explicar o } \\
\text { contéúdo a ele relacionado e solicitar que os alunos o acessem novamente com o objetivo } \\
\text { de realizar uma determinada atividade que dependa de informaçóes apresentadas pelo } \\
\text { objeto para ser desenvolvida, como por exemplo o desenvolvimento de um Projeto. } \\
\text { Utilizar o vídeo após a explicaşão de um determinado conteúdo, mostrando-o sem } \\
\text { interrupcónes e logo depois discutir o que aprenderam a mais, ou foi acrescentado na } \\
\text { aprendizagem com a utilização dessa ferramenta digital. O conteúdo pode ser utilizado } \\
\text { como forma complementar ao que já foi trabalhado de outras formas. }\end{array}$ \\
\hline & $\begin{array}{l}\text { Dizer aos alunos que os objetos facilitarão o seu aprendizado e permitirão que participem } \\
\text { mais ativamente da aula. Apresentar ou solicitar que os alunos acessem o objeto } \\
\text { relacionado ao tema. Explicar o conteúdo a ele relacionado e solicitar que os alunos o } \\
\text { acessem novamente com o objetivo de realizar uma determinada atividade, como um } \\
\text { exercício, a leitura ou produção de um relatório que dependa de informações apresentadas } \\
\text { pelo objeto para ser desenvolvida. }\end{array}$ \\
\hline
\end{tabular}

Fonte: O autor.

13 O documento inicial criado com o objetivo de compartilhar estratégias de ensino com RD ou objetos de aprendizagem, especialmente com professores, na área de Ciências e Biologia está disponível no endereço: https://espe.univ-amu.fr/sites/espe.univ-amu.fr/files/article/ b01relatorioguiaobjetocienciasbiologiafev2015finale.pdf 
Quadro 3 - Professores de Física e Química14

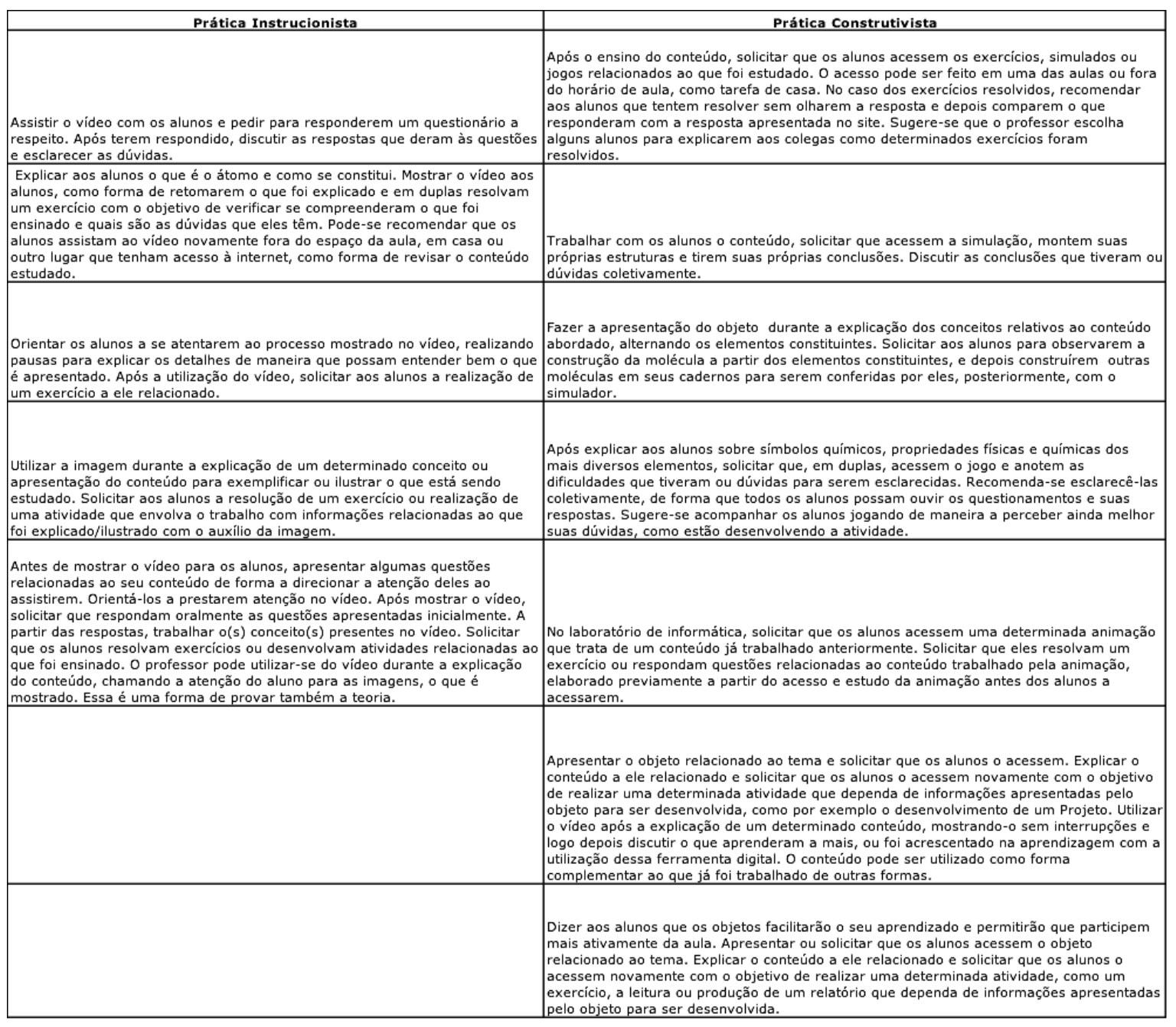

Fonte: O autor.

14 O documento inicial criado com o objetivo de compartilhar estratégias de ensino com RD ou objetos de aprendizagem, especialmente com professores de Física e Química, está disponível no endereço:

https://espe.univ-amu.fr/sites/espe.univ-amu.fr/files/article/ b02relatorioguiaobjetofisicaquimicafev2015finale.pdf 


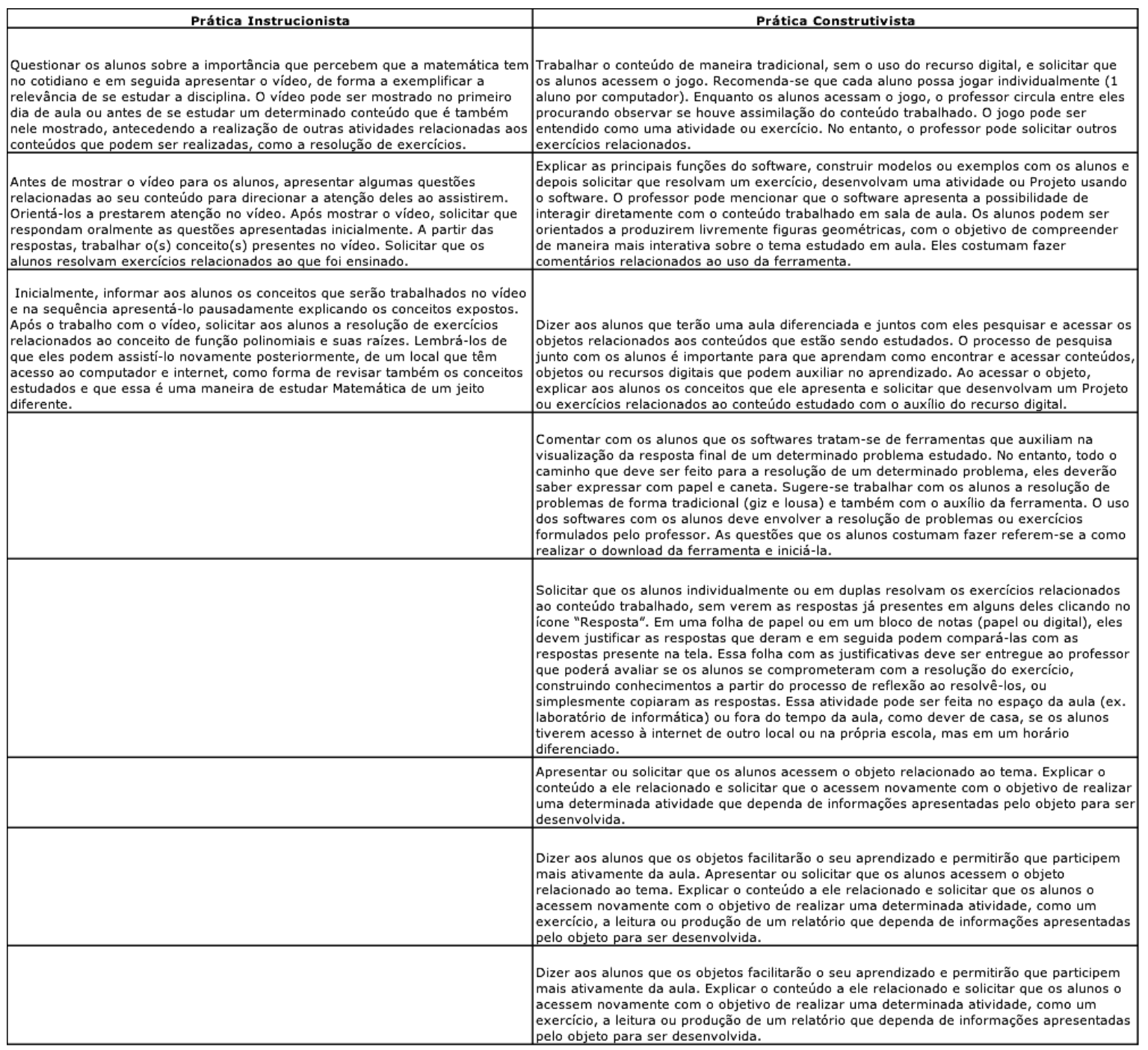

Fonte: O autor.

15 O documento inicial criado com o objetivo de compartilhar estratégias de ensino com RD ou objetos de aprendizagem, especialmente com professores de Matemática, está disponível no endereço:

ht tps://espe.univ-amu.fr/sites/espe.univ-amu.fr/files/article/ b03relatorioguiaobjetosmatematicafev2015finale.pdf 